\title{
Analysis on Impasses in International Business Negotiations
}

\section{Gao Yanhua}

School of Business Administration, Xi'an Eurasia University, Xi'an, China

Email address:

gaoyanhua@eurasia.edu

\section{To cite this article:}

Gao Yanhua. Analysis on Impasses in International Business Negotiations. International Journal of Economics, Finance and Management Sciences. Vol. 9, No. 5, 2021, pp. 215-220. doi: 10.11648/j.ijefm.20210905.17

Received: October 8, 2021; Accepted: October 30, 2021; Published: November 5, 2021

\begin{abstract}
During international business negotiations, the stakeholders of business activities in different countries or regions negotiate the various elements of a transaction for the purpose of economic interests or in order to complete a transaction. International business negotiations are very important in international business activities which are means to solve the conflict of interests and achieve common interests among the subjects of business activities of different countries. Impasses always appear in all phases of international business negotiations, which directly determines the success of negotiations. The paper focuses on Categories of Impasses, Causes of the Impasse, Principles for Avoiding the Impasse, Approaches to Deal with the Potential Impasse, The Golden Opportunities for Dealing with the Impasse, and Ways of Breaking the Impasse to deal with impasses of international business negotiations during all procedures to fulfill the anticipated objectives. Causes of impasse, as Divergent Objectives, One Party Has All the Say in the Negotiation, Be Overly Silent and Be Slow in Reacting, Extreme Sentiment, Negotiators Who Have Low Quality, Barrier to Information Communication, Use Both Hard and Soft Tactics to Procrastinate, A Change in the External Environment; and Approaches to Deal with the Potential Impasse as, First partial approval, then total negation, Repeat the counterpart's opinion first, then weaken it, Persuade the other party with their own opinions, Impel the other party to make self-denial by raising questions,. Persuade the other party by standing on their side, Generalize and summarize, Induce the other party by asking back, Humor, Present a gift properly, Outside communication are analysed in details to provide guidance to the negotiators.
\end{abstract}

Keywords: International, Business, Negotiation, Impasses

\section{Introduction}

International business negotiations refer to the process in which the stakeholders of business activities in different countries or regions negotiate the various elements of a transaction for the purpose of economic interests or in order to complete a transaction. International business negotiations are very important in international business activities which are means to solve the conflict of interests and achieve common interests among the subjects of business activities of different countries. Impasses always appear in all phases of international business negotiations, which directly determines the success of negotiations. Analysis on the causes and tactics to handle impasses will make great sense to a successful negotiation.

\section{Definition of Impasse}

In the process of substantial negotiation, the parties involved may refuse to give in and fall into a dilemma for a certain reason. [1] This kind of situation is the so-called negotiation impasse. An impasse arises when, in the ultimate analysis, the parties involved stick to their own interests and fail to reach an agreement on a certain issue. In other words, their expectation of their own interests, the failure to have the same position or opinion on a certain issue, and their unwillingness to make further concessions lead to a deadlock. [2]

\section{Categories of Impasses}

Narrowly defined, the negotiation is a process in which the parties exchange their opinions and sign a contract. In this 
perspective, the impasses are categorized into the one in the initial stage of negotiation, the one in the middle stage of negotiation and the one in the later stage of negotiation. [3]

The initial stage of the negotiation is an important period when both parties understand each other, create a good atmosphere and establish friendly relationship, of which both parties have great expectation. But owing to misunderstanding or one party's inadequate preparation, the other party may get hurt emotionally. Thus, an impasse arises and both parties wind up the negotiation hastily. [4]

The middle stage of the negotiation is a substantial period when both parties discuss the transaction contents including the technology, price and terms and conditions of a contract in great detail. Due to the difference in the interests of the parties involved, the negotiation is likely to develop into a conflict. The stalemate in the middle stage of negotiation often tends to be changeable. If the both parties are able to communicate again, the stalemate will be easily solved; If both parties are unwilling to compromise over critical issues and procrastinate the negotiation, the problems will be unsettled. The middle stage is a period when the impasse is the most changeable and when the breakdown of the negotiation is most likely to arise. [5]

The later stage of the negotiation is a period when both parties reach an agreement. Both parties often need to further discuss the implementation details such as the project acceptance and the terms of payment after they have solved the critical issues such as technology and price. In this stage, the words of the terms and conditions of a contract as well as the negotiators' tone may easily contribute to a dispute. But in the impasse of this stage, the negotiation will be ended smoothly only if one side is somewhat broad-minded and concedes a little. [6] Even though the impasse in this stage is easier to deal with than the one in the middle stage of negotiation, one can not relax his vigilance. Otherwise, all the previous efforts will be wasted. [12]

Broadly defined, the negotiation always goes through the whole process of negotiation. Therefore, an impasse is likely to arise at any time and in any place accompanying the whole process of cooperation. Generally speaking, the process of project cooperation can be divided into the agreement period and execution period of a contract. [11] the impasse in the agreement period and the impasse in the execution period. The former arises when the two parties disagree on the opinions in the consultation stage. The latter arises when both parties have discrepant opinions due to their different understanding of the terms and conditions in executing the contract, when one side shirks and shifts the responsibility to the other side simply because of the unexpected conditions, when one side is seriously dissatisfied because the other side is unable to implement the agreement or when the division of the responsibility is indefinite.

\section{Causes of the Impasse}

During the process of negotiation, an impasse arises with regularity. The parties involved can resolve the impasse without difficulty and reach an agreement as long as they are able to judge and master the causes of the impasse correctly. Impasse or stalemate can arise mainly for the following eight reasons. [9]

\subsection{Divergent Objectives}

During the process of negotiation, when both parties insist on their own views and refuse to make concessions, they are likely to dispute with each other. In this case, the apparent opposing stances conceal the real interests of both parties. Meanwhile, since both parties are unwilling to concede so as to save the face, they force the counterpart to change their position by matching the willpower with each other, even threaten to quit the negotiation. [13] As a result, the negotiation will be delayed and the negotiators will lose the confidence, which makes it more difficult to reach an agreement. It is common that an impasse arises from the dispute over opinions. In other words, the main reason for an impasse is that the negotiators make the mistake of sticking to their own positions and viewpoints.

\subsection{One Party Has All the Say in the Negotiation}

The business negotiation is a process in which negotiators exchange information and negotiate with each other orally. When one party sets forth their own view unceasingly, they may overlook the counterpart's response and their opportunity to state their own views. Moreover, one party would probably believe they have adequate grounds for fear that the other party may not understand it, or they can only win their counterpart's understanding and trust by stating their own views from different perspectives again and again rather than giving the other party the chance to do so. In fact, such practice deprives the other party of the right to speak and thus results in an impasse.

\subsection{Be Overly Silent and Be Slow in Reacting}

When one party, for whatever purpose, is unable or unwilling to communicate fully and is silent overly, or they seemingly listen with attention but actually are slow in reacting, it will be easy for them to arouse the counterpart's suspicion and vigilance, exerting a psychological pressure on the other party and leading to the negotiation impasse. [14]

\subsection{Extreme Sentiment}

When a negotiator demonstrates the intense sentiment in the topic under discussion excessively, for instance, proposing illogical suggestions or showing strong personal prejudice, it is disadvantageous to carry out a negotiation due to the partial understanding of certain problems. The negotiators' understanding of the information is often restricted by their occupation, education background, expertise or even their bias against the culture of the counterpart. Therefore, [10] their understanding of the information is subjective and partial, even totally contrary to the substantial information. Under such circumstances, both parties can hardly reach an agreement on the topic for discussion, which may lead to an impasse easily. 


\subsection{Negotiators Who Have Low Quality}

The quality of the negotiators is often the key factor that determines whether the negotiation is successful or not. The low quality of a negotiator may be reflected by the inappropriateness of the time or approaches of adopting the strategies, lack of knowledge or experience and the fault in negotiation skills, which may lead to a negotiation impasse.

\subsection{Barrier to Information Communication}

The key point to clear information communication is that people in communication can not only receive their counterpart's information distinctly, but also understand its superficial meaning as well as the ideological implication correctly. [15] In the process of business negotiation, the distortion of information communication is a common phenomenon, which leads to the misunderstanding and dispute between two parties. Thus, the negotiation will fall into a deadlock. The distortion of information transfer or understanding may be verbal or non-verbal. In other words, the error of understanding the information may be reflected on the aspects of spoken and written expression, facial expressions, gestures and postures.

The information communication barrier in business negotiation is the obstacle that two parties encounter in comprehending their counterpart's conditions, opinions, cooperative intention, as well as the terms and conditions of the transaction. Such barrier may be caused by their difference in cultural background, occupations, education background or one side's unwillingness to accept the advice raised by the other side due to the mental factors.

\subsection{Use Both Hard and Soft Tactics to Procrastinate}

The negotiation is likely to fall into an impasse or breakdown when the negotiators procrastinate the negotiation incessantly, adopt both hard and soft tactics just to achieve a certain private objective. [16] For example, a negotiator entrusts the other representative with the negotiation on the excuse that he has to deal with an emergency at the moment but the substitute doesn't say yes or no, which delays the senseless negotiation obviously. Such practice is not only quite disrespectful, but also hides other implication or motive, thus incurs the other party's displeasure and results in an impasse.

\subsection{A Change in the External Environment}

In the process of the negotiation where there is a change in the external environment, one on hand, the negotiator feels embarrassed to break his promise; on the other hand, he is worried that the other party would refuse it if he breaks a promise. However, the negotiator delays and shelves the negotiation, with no intention to sign a contract, reaching the limit of the other party's patience and leading to an impasse.

\section{Principles for Avoiding the Impasse}

When an impasse arises in the negotiation, negotiators should analyze its causes and where the specific difference lies, research into the specific strategies and tactics of breaking an impasse actively, confirm the course of action and finally handle the negotiation impasse properly.

Divergent opinions are common in the negotiation. The opposing ideas are barrier to a smooth negotiation, but, from another perspective, they also imply that the parties involved are interested in the topic for discussion or wish to reach an agreement. Therefore, negotiators are supposed to embrace the contrary views sincerely. Both parties should negotiate about the opposing opinions with a calm and cordial attitude rather than refute them in a tit-for-tat tone. [17] Meanwhile, negotiators should possess strong ability of self-control, prevent the argument from developing into a quarrel and pay attention to the mildness and artistry in language. If both parties can uphold the belief in a mutually beneficial negotiation, discuss the effective ways to satisfy their need together, the factors that form the stalemate will be destroyed in the bud. All the above mentioned are the principles for avoiding the impasse. Then, if an impasse is about to or has arisen in the process of the negotiation, the following approaches are provided to solve it skillfully.

\section{Approaches to Deal with the Potential Impasse}

The potential impasse could be dealt with properly in indirect or direct ways. The so-called indirect ways refer to a practice in which the negotiators deny their counterpart's opinions tactfully with the help of the relevant issues or reasons.

The indirect approaches to deal with the potential impasse are as follows.

\subsection{First Partial Approval, Then Total Negation}

When it comes to the different views of both parties, a negotiator could confirm the counterpart's view partially and slightly in his speech, then negates it totally, indirectly and tactfully with well-grounded reasons. [18]

\subsection{Repeat the Counterpart's Opinion First, Then Weaken It}

The negotiator repeats the counterpart's opposing view in a mild and indirect tone first, then points at the opposing view and makes a reply. He will not make any change to the idea when repeating it so that the negotiation atmosphere will be eased off. However, such approach could not be applied mechanically. Instead, the negotiator should study the counterpart's mental activity and employ the approach based on different situations.

\subsection{Persuade the Other Party with Their Own Opinions}

A negotiator can use his counterpart's opinion to persuade him directly or indirectly so as to change his mind.

\subsection{Impel the Other Party to Make Self-denial by Raising Questions}

A negotiator can raise a question instead of answering the 
question directly so as to make the other party negate his original opinion in the process of answering the question.

The direct approaches to deal with the potential impasse fall into the following categories. [19]

\subsection{Persuade the Other Party by Standing on Their Side}

When one side in the negotiation sticks to his own opinion, the other side should not only convince him with sufficient grounds and facts and closely-knit logic, but also satisfy his need to a certain extent.

\subsection{Generalize and Summarize}

The negotiator should generalize, sort out or sum up the counterpart's opposing views and then explain and illustrate them with a clear aim so as to weaken the counterpart's views or opinions.

\subsection{Induce the Other Party by Asking Back}

Provided a puzzling and oppressive atmosphere arises, the negotiation tends to fall into an impasse. The reasons for such situation are quite complex. It may be attributed to the change in the negotiator's psychology, or caused by the fact that one side does not reveal their objection. [20] The negotiator can ask a question in reply with the help of the opinion raised by the counterpart, which not only helps to prevent the negotiation from falling into a deadlock but also persuade the other party effectively.

\subsection{Humor}

When a stuffy atmosphere arises in the negotiation, the negotiator could use the tactic of humor to make the dangerously explosive and tense atmosphere vanish. As a result, the mental pressure of both parties will be alleviated and greater vigor will be invested into the negotiation with proper relaxation. [21]

\subsection{Present a Gift Properly}

When the negotiators contact with each other, they can keep up a friendship by exchanging presents appropriately, showing the expectation of establishing a friendly relationship definitely.

\subsection{Outside Communication}

Even though the outside communication is a kind of informal negotiation where both parties can exchange opinions without constraint to remove the obstacles and avoid the impasse, the deadlock in the formal negotiation can also be solved and the misunderstanding can be explained away through outside communication. [22]

\section{The Golden Opportunities for Dealing with the Impasse}

Since the negotiations are changeable and complicated, adopting the corresponding measures to deal with the stalemate at different times will have different effects. The following are the relevant approaches which could be adopted when it comes to the golden opportunities for dealing with the impasse.

Respond to the opposing opinion in time. Both parties hope that the other party will have respect for and pay attention to their ideas. As a result, if one side cannot give a definite answer, the other side will encounter mental disorder and the potential impasse will arise. In this sense, the negotiator from one side is expected to make a reply to his counterpart's opposing views in time. If he can't do so, he also needs to take the initiative to explain himself explicitly so as to show his sincerity.

Delay making a reply properly. Such tactic can be employed when negotiators encounter thorny issues in the negotiation. When one party cannot make a satisfactory reply to the opposing views raised by the other party, or they don't have adequate proofs to refute the counterpart's opinions but will be thrown into an unfavorable situation if they answer in time, or they are confident of controlling the situation, or the opposing views raised by the other party deviate from the topic obviously or when they become irrational and unleash their emotions, under these circumstances can they postpone the negotiation properly before making a reply, which will produce good results. However, the delaying time should not be too long and the negotiator from one side had better make himself clear to the counterpart. [23]

Take preemptive measures. Supposing a negotiator can accurately predict the opposing opinions that his counterpart is about to raise based on the relevant situation, the impasse will be avoided and removed effectively when the negotiator seizes the opportunity to raise a question which could be used as his argument later and persuades the other party to recognize the question again. [24]

\section{Ways of Breaking the Impasse}

\subsection{Resort to Lateral Negotiation}

The lateral negotiation refers to a way in which negotiators talk over the topics for discussion one by one fixed in advance. When their opinions diverge on a certain topic, they will set the topic aside rather than adhere to it or never stop unless they reach an agreement. Then they continue to discuss the other topics and go round and round until all the issued have been settled. Such way of negotiation would have less resistance and more room for consultation.

\subsection{Change the Date of the Negotiation}

If the negotiation falls into a severe deadlock and could hardly proceed, both parties can agree on the adjournment and decide on the time and place of the negotiation again. Pay attention to restate your opinion so as to arouse the other party's attention and give them adequate time for consideration before the adjournment. [25] 


\subsection{Change the Negotiation Environment and Atmosphere}

A tense negotiation atmosphere is likely to make the negotiators feel depressed and agitated. If your side are the hosts, you could arrange relaxing recreational activities such as sightseeing. In the activities, negotiators will proceed to exchange opinions with each each on the deadlock issues, thus removing the obstacles in a relaxing atmosphere and making the negotiation take a favourable turn.

\subsection{Reminisce}

Negotiators can weaken the antagonism between two parties with the help of reflecting on the past cooperation and emphasizing the common interests and past cooperative achievement.

\subsection{Replace the Negotiator or Request the Leader to Mediate Between Two Parties}

If the stalemate hasn't been eased off with various efforts, one side is allowed to substitute the negotiator as long as they obtain the consent of the other party. And they can also request the leader to appear personally when it is necessary. The mental pressure of the other party will be weakened and their attitude will be relaxed when they receive the high-ranking treatment, thus eliminating the impasse. [26]

\section{Conclusion}

Even thouth impsses always happen during all stages of business negotiation, we can find out the couses and tactics to handle impasses when it occurs. Suitable approaches will be benefitial to a successful negotiation. Approaches to Deal with the Potential Impasse as, First partial approval, then total negation, Repeat the counterpart's opinion first, then weaken it, Persuade the other party with their own opinions, Impel the other party to make self-denial by raising questions,. Persuade the other party by standing on their side, Generalize and summarize, Induce the other party by asking back, Humor, Present a gift properly, Outside communication are analysed in details to provide guidance to the negotiators.

\section{References}

[1] Haensel Jennifer X., Ishikawa Mitsuhiko, Itakura Shoji et al. Cultural influences on face scanning are consistent across infancy and adulthood [J] Infant Behavior and Development, 2020, 61 .

[2] Ji Li Jun, An Sieun Cultural Differences in People's Responses to Accidents [J] Journal of Loss and Trauma, 2021, 26 (3).

[3] Xie Guanhui, Paik Yonjeong Cultural differences in creativity and innovation: are Asian employees truly less creative than western employees? [J] Asia Pacific Business Review, 2019, 25 (1).

[4] Te Hsin Chang, Anita R. Tucker, Christine Lynn Norton et al. Cultural issues in adventure programming: applying Hofstede's five dimensions to assessment and practice [J] Journal of Adventure Education and Outdoor Learning, 2016, 17 (4).
[5] Eero Vaara, Riikka Sarala, Günter K. Stahl et al. The Impact of Organizational and National Cultural Differences on Social Conflict and Knowledge Transfer in International Acquisitions [J] Journal of Management Studies, 2012, 49 (1).

[6] Pak-Hang Wong Cultural Differences as Excuses? Human Rights and Cultural Values in Global Ethics and Governance of AI [J] Philosophy \& Technology, 2020, 33 (prepublish).

[7] Yuping Zeng, Oded Shenkar, Seung-Hyun Lee et al. Cultural differences, MNE learning abilities, and the effect of experience on subsidiary mortality in a dissimilar culture: Evidence from Korean MNEs [J] Journal of International Business Studies, 2013, 44 (1).

[8] Na Jinkyung, Huang Chih Mao, Park Denise C. When Age and Culture Interact in an Easy and Yet Cognitively Demanding Task: Older Adults, But Not Younger Adults, Showed the Expected Cultural Differences [J] Frontiers in Psychology, 2017.

[9] Deb Roy DIVERSITY, EQUITY \& INCLUSION [J] Professional Safety, 2021, 66 (4).

[10] Lobban Glenys Encountering the "Other": Reflections on Skoufalos' "Couples Therapy: A Painful Hour, a Pained History" [J] Psychoanalytic Perspectives, 2021, 18 (1).

[11] Shrikant Natasha Cultural difference as a resource for arguments in institutional interactions [J] Communication Monographs, 2021, 88 (2).

[12] Mojaverian Taraneh, Hashimoto Takeshi, Kim Heejung S. Cultural Differences in Professional Help Seeking: A Comparison of Japan and the U.S. [J] Frontiers in Psychology, 2013.

[13] Al Nasser Mohammad, Yusoff Rushami Zien, Islam Rabiul et al. Cultural Differences Identification and its Effect on E-Service Quality Perception [J] American Journal of Economics and Business Administration, 2013, 5 (2).

[14] Mangan James Piaget's Theory and Cultural Differences: The Case for Value-Based Modes of Cognition [J] Human Development, 1978, 21 (3).

[15] Božena Radiměřská Angličtí cestovatelé ve středovýchodní Evropě v sedmnáctém a osmnáctém století: Studie vnímání prostoru [J] AUC PHILOSOPHICA ET HISTORICA, 2015, 2010 (1).

[16] Julia Backmann, Rouven Kanitz, Amy Wei Tian et al. Cultural gap bridging in multinational teams [J] Journal of International Business Studies, 2020, 51 (prepublish).

[17] Meina Liu Cultural Differences in Goalâ directed Interaction Patterns in Negotiation [J] Negotiation and Conflict Management Research, 2011, 4 (3).

[18] He Tianyu, Williams Melissa J. Interdependence and reflected failure: Cultural differences in stigma by association $[\mathrm{J}]$ Journal of Experimental Social Psychology, 2021, 95.

[19] Messner Wolfgang, Adler N. J., Alesina A. et al. Connections Between Cultures: Using Empirical Distributions for Measuring Cultural Differences [J] Journal of Cross-Cultural Psychology, 2021, 52 (2).

[20] Hanna Edwards Ashley A. Food for thought: An exercise in third-culture building [J] Communication Teacher, 2021, 35 (4). 
[21] Peeters Carine, Dehon Catherine, GarciaPrieto Patricia The attention stimulus of cultural differences in global services sourcing [J] Journal of International Business Studies, 2015, 46 (2).

[22] Yumeng Peng, Xiang Zhou A cross-cultural analysis of the modes and effectiveness of collaborative production of knowledge on Quora [J] Aslib Journal of Information Management, 2020, 73 (2).

[23] Dheer Ratan JS, Lenartowicz Tomasz, Peterson Mark F Mapping India's regional subcultures: Implications for international management [J] Journal of International Business Studies, 2015, 46 (4).

[24] Oishi Shigehiro, Diener Ed, Napa Scollon Christie et al. Cross-Situational Consistency of Affective Experiences Across Cultures. [J] Journal of Personality and Social Psychology, 2004, 86 (3).
[25] Reed H. B. Review of Race and Marriage. [J] Psychological Bulletin, 1910, 7 (12).

[26] Michael W. Morris, Kwok Leung Creativity East and West: Perspectives and Parallels [J] Management and Organization Review, 2010,6 (3).

\section{Biography}

Gao Yanhua, Male, born in July 1984, PHD in business administration, senior economist and associate professor in Xi'an Eurasia University. 